\title{
Experiments determining the height of the pressure and the time required to clean the water purification filter
}

\author{
Saparuddin Saparuddin ${ }^{1 *}$ and Maryo Pitanda Eisenring ${ }^{1}$ \\ ${ }^{1}$ Department of Civil Engineering, Universitas Tadulako, Palu, Indonesia
}

\begin{abstract}
The water treatment process to get water that meets the requirements of drinking water is carried out using sand filters as the main ingredients in addition to gravel, charcoal, and fiber. This water treatment can effectively produce drinking water that is needed, the use of a filter for a long time will cause blockage by dirt stuck on the surface of the sand filter, so it cannot be used continuously without being cleaned regularly. This study aims to determine the water pressure needed to clean the dirt that clogs the sand filter and the length of the filter washing cycle. Using laboratory experiments on a J-shaped filter container model of crosssection plastic pipe $\varnothing 7.5 \mathrm{~cm}, \varnothing 10 \mathrm{~cm}, \varnothing 15 \mathrm{~cm}$, and $\varnothing 20 \mathrm{~cm}$ filled with sand grading 0.15 to $0.6 \mathrm{~mm}$ as thick as $50-60 \mathrm{~cm}$, channeling pressurized water through the outlet into the sand filter and out through the overflow pipe. The results showed that a water level of $200 \mathrm{~cm}$ above the datum was able to push dirt and clean the filter after being pressed for 600 seconds.
\end{abstract}

\section{Introduction}

Human life takes place because it is supported by the presence of sufficient water and qualifies. Water is a chemical compound resulting from the bonding element of hydrogen (H2) which is fused with the elements oxygen $(\mathrm{O})$ is a very important resource, both for the lives of humans, animals and plants, therefore needs to be managed and maintained the quality and quantity.

On this earth, about $67 \%$ consists of water, most of which is sea water. Freshwater spread unevenly between one place and another. So it is not unfamiliar if in a given place water is very abundant, whereas in other places the water is very less. Water on Earth through a cycle, means water from somewhere to flow at ground level, there seeps into the ground, and there evaporates into space then falls into the rainwater and returns to flow. Water in its cycle is contaminated as a result of contamination, and since it is easy to dissolve other substances the water could be contaminated by the passed substances.

Indonesian population mostly use surface water, especially river water as clean water. Research that has been done [1], 70-75\% of rivers in 33 provinces in Indonesia have been polluted, the dominant pollutants that pollute the river come from domestic waste (household waste). Joko Susanto at al. [2] Clean water is water that is suitable for consumption, clear, odorless, tasteless, and must meet health requirements.

Before the denseness of the population, the quality of the river water is good enough so that no processing is required before consumption, and water required taken directly from the source with a simple container. The dense of the population and the development of

\footnotetext{
* Corresponding author: Sapar_59@yahoo.co.id
} 
industries that throw away waste materials into water bodies, river water becomes more polluted, and water purification becomes necessary [3]. Joko Susanto et al. [2] stated that dirty water cannot be consumed directly, but it must be processed first.

To improve the basic needs of the community about clean water, it needs to be adjusted to the level of ability of technology in society. One alternative is to use a simple water treatment with grained filter media such as sand. Water treatment at a turbidity of 50 NTU using J-shaped plastic pipes that filled with $50 \mathrm{Cm}$ to $60 \mathrm{~cm}$ thick sand effectively reduces the turbidity of water to below 5 NTU. It does not significantly influence the size of the plastic pipe cross section used against the water quality of the filter, the smaller the crosssection of the pipe that used the faster it washing the filter [4].

\section{Literature review}

\subsection{Water quality requirements}

The quality of raw water determines the quality of clean water as a source of water. The quality of water consumed by society refers to the provisions World Health Organization (WHO) and local government policies, and other provisions that apply to local communities, the feasibility of water for consumption is determined based on physical quality, chemical quality, and biological quality and requirements of radioactivity.

Approximately $80 \%$ of all diseases in developing countries are caused by the condition of clean water and poor sanitation (polluted), pollution of surface and ground water from agriculture [5]. Litidamu at al. [6] Domestic and industrial activities have not been regularly monitored and recorded as a problem. This may be caused by the absence of problems or a lack of monitoring facilities in Pacific island countries. The quality and accessibility of drinking water are very important for human health. Drinking water may contain diseasecausing agents and toxic chemicals and to control risks to public health, and systematic water quality control is required [7].

\subsection{Water filtration}

The process is conduction with a sand filter that has a length of $51 \mathrm{~cm}$, consisting of three layers and water can be filtered with a speed of $0.022 \mathrm{~m} / \mathrm{s}$, water loss is estimated to be 0.2 liters for the first 5 liters and will decrease with screening duration [8]. Water filtration with turbidity of 50 NTU will experience a decrease in discharges along with the duration of filter use until the filter time does not remove water (filter clogged) and need to be washed to reactivate [4].

\subsection{Water pressure}

As water flows through the pipe, friction along the wall limits the speed. On the surface of the water in the tank constant, average speed decreases with increasing length of the tube. For laminar flow of fluid through a cylindrical pipe length [8], Hagen-Poiseuille Eq. 1 shows the water pressure decreases when water flows through the pipes.

$$
\Delta P=\frac{8 \mu}{Q \pi r^{4}} \times L
$$

where $\Delta P$ is the change in pressure, $\mu$ is the dynamic viscosity of the liquid, $\mathrm{r}$ is the radius of the tube, $L$ is the length of the tube, and $Q$ is the volumetric flow.

Since the tube is cylindrical, the volumetric flow rate in terms of velocity $v$ is: 


$$
Q=\pi r^{2} v
$$

Combining Eq. 1 and 2, the relationship between velocity and length of tubing is:

$$
v^{-1}=\frac{8 \mu}{\Delta \operatorname{Pr}^{2}} \times L
$$

Eq. 3 is applicable to fluid flowing continuously in a tube. Since the still water in the tank must first enter the end of the tube, it is predicted that a constant must be included in Eq. 4:

$$
v^{-1}=\frac{8 \mu}{\Delta \operatorname{Pr}^{2}} \times L+C
$$

Since this equation applies to non-turbulent flow, it may not perfectly model the situation studied. For the head of water used in this investigation, the velocity of the water flowing through the tube is relatively high, therefore some turbulence may be expected. Reynolds number can be used to distinguish the type of flow.

$$
\operatorname{Re}=\frac{Q D_{h}}{v A}
$$

where $D_{h}$ the hydraulic diameter, $v$ is the kinematic viscosity, and $A$ is the pipe cross sectional area. For water flowing in a pipe, Reynolds numbers of less than 2300 are considered to be the laminar type, while turbulent flow begins at values of 4000 and above.

The filter sand medium after being used for a long time will become dirty and clog the flow of water, especially if the raw water contains too much suspended solids. In this condition filter media quickly saturated and need to be washed $[9,10]$.

\section{Research methods}

\subsection{Installation of water purification}

This research uses a water purification installation in the form of letter $\mathrm{J}$ equipped with supporting tools such as raw water reservoir tendon, pump, connecting pipes, and others such as Fig. 1. The working process of this cleansing installation also serves to wash the filter sand in the filter container, the process of filtering/ washing the filter with the following steps:

1. The turbidity of raw water at storage tank 1) is regulated according to raw water standard that can be processed into clean water for drinking.

2. The water in the storage 1) pumped, 2) through a pipe, 3) into the tank 4), to maintain the water level in the upper reservoir, the excess water flows through a pipe 5) back to the lower reservoir 1).

3. Water purification is done by flowing raw water from the tendon 4) through the pipe 6) into the treatment plant 12) passing through sand filter 11), Ijuk 9), activated charcoal 10) then Ijuk 9), gravel 8), and out on out let 14) into clean water.

4. The filter washing process, the water from the upper tendon 4 is connected with the washer slam 7) to the outlet 14), the water passes through/ pushes the gravel layer 8), to the filter sand layer 11). Dirt entrained in a layer of sand, escape and flow out 13) along the water purifier, and a layer of sand to be clean and filter can be used again. 


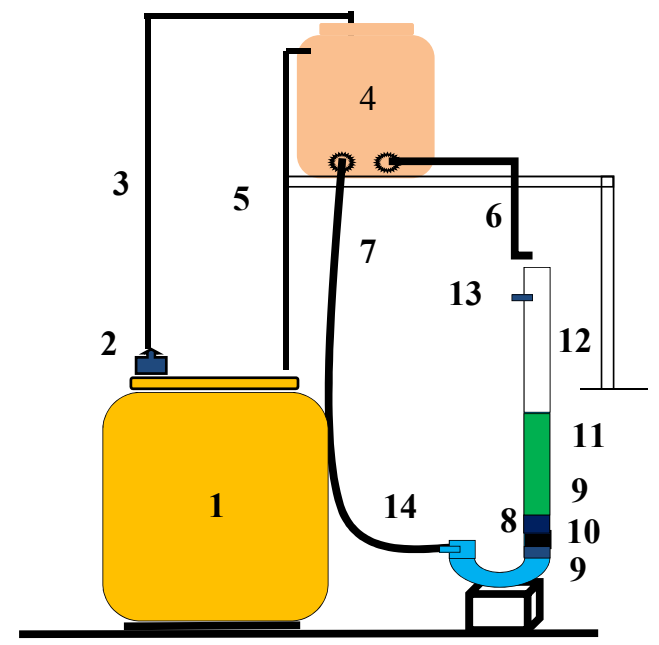

1. Raw water storage tanks..

2. Pumps raise raw water

3. Pipe the pump to the upper tank.

4. Tandon on raw water reservoir

5. Water surface stabilization pipe.

6. Raw water pipe

7. Pipe washing Filter

8. Gravel strainer

9. Fibers filter

10. charcoal active

11. sand filter

12. Raw water chamber

13. The sewer dirty water

14. Clean water dispenser/pressure when washing the filter..

Fig. 1. Installation of water purification.

\subsection{The water pressure and time washing the filter}

The water pressure flowing in the washing sieve process is calculated by Eq. 1. The discharge that flows during filter washing is measured using a water meter such as Fig. 4. The water pressure required to push the dirt on the sand layer is as much as possible to remove the dirt with the washing water out of the sieve and not to bring the sand out of the sieve container, for that need to note the speed of water that passes through the sand layer during washing. The pressure is too large to cause the filter sand to lift up and out with dirt, while the pressure is weak then dirt cannot be pushed/ lifted, even dirt can enter on the sand layer so that the sand layer does not become clean.

\section{Results and discussion}

This research was conducted with a sieve washing experiment to determine the height of water pressure required to remove the dirt covering the sand filter layer and to measure the time required for the washing process until it was eligible for reuse.

\subsection{Washing the water filter}

Water purification experiments using plastic pipe-shaped letters $\mathrm{J}$, using a filter of a graded sand layer of $0.15 \mathrm{~mm}$ to $0.6 \mathrm{~mm}$, the thickness between $50-60 \mathrm{~cm}$ will decrease the discharge throughout the filter usage, for it is necessary to wash periodically in order to be reused.

Washing slow sand filter, carried out by streaming water through a filter, closing the outlet and open the inlet until the water overflows over the sand filter surface, pools of water are rocked slowly, then the dirt on the surface of the sand filter will be lifted and flow out until the dirt on the surface of the sand to be clean.

The filter sand washing system in this study was carried out on a sieve container by utilizing water pressure of the currents through the outlet, water pressure through layers: gravel, fibers, charcoal, fibers, layers of the sand filter until the layer of dirt is suspended above the sand surface. With water pressure on the sand then turbulence occurs, because 
the weight of sand is greater than the water impurities, the sand remains below, and the dirt breaks away and then flows with the dirty water out of the filter, the sand filter becomes clean, and the filter can be reused.

In this research, filter washed, when the initial discharge Fig. 2 increasingly decreased Fig. 3, after purification, is used more than 50 hours.

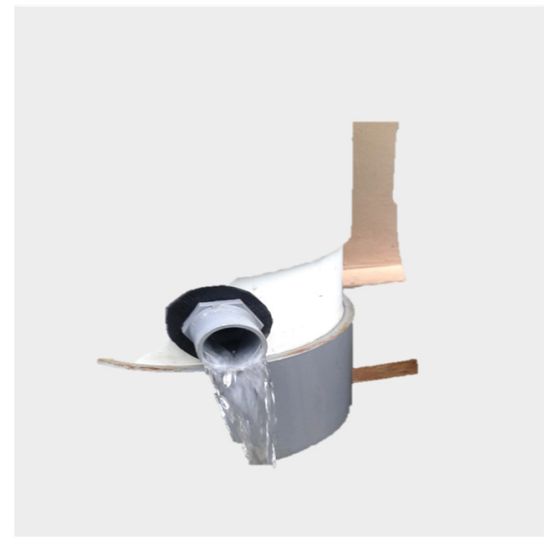

Fig. 2. Initial discharge of filter usage.

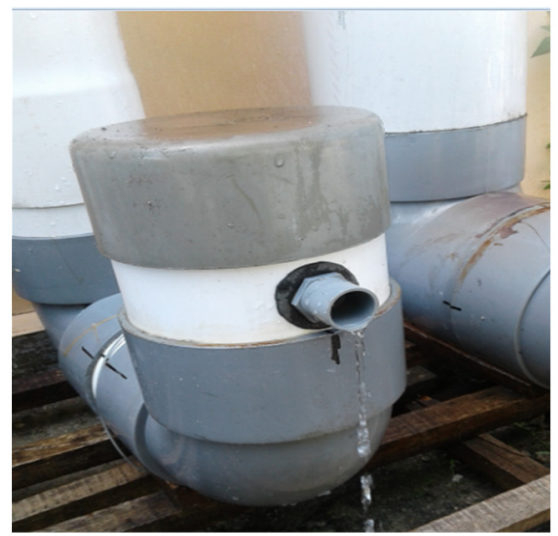

Fig. 3. Discharge after 50 hours filter usage.

Initial use of cleansing, discharge 181 liters/hour of image 2, after 50 hours of use of the cleansing, discharge decreased to 13 liters/hour of Fig. 3, no longer effective produce water required, so the filter needs to be cleaned. Model washing the filter as in Fig. 4 and 5.

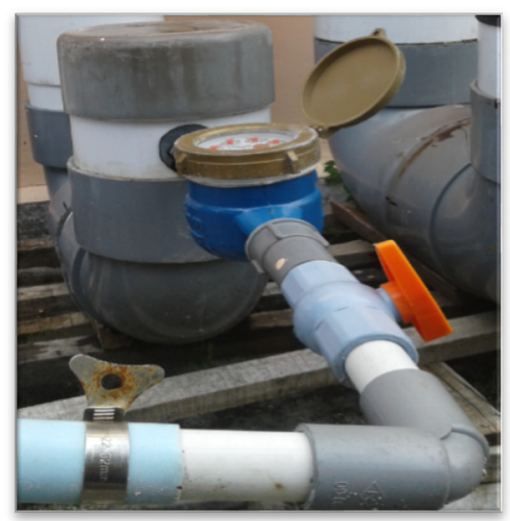

Fig. 4. Measuring discharge strainer laundering.

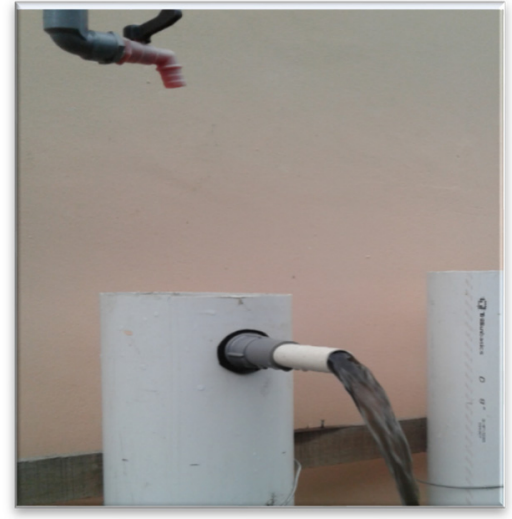

Fig. 5. Dirty water out of purification.

The washing process of a water filter, by passing pressurized water through a wash slam connected to a water tank above it to a clean water outlet pipe Fig. 4, water that flows through a layer of dirty sand, flowing out with dirt Fig. 5. The level of turbidity of the water coming out of the wash based on the length of the washing time of the filter as shown in Fig. 6. and the result is like the graph of Fig. 7. 


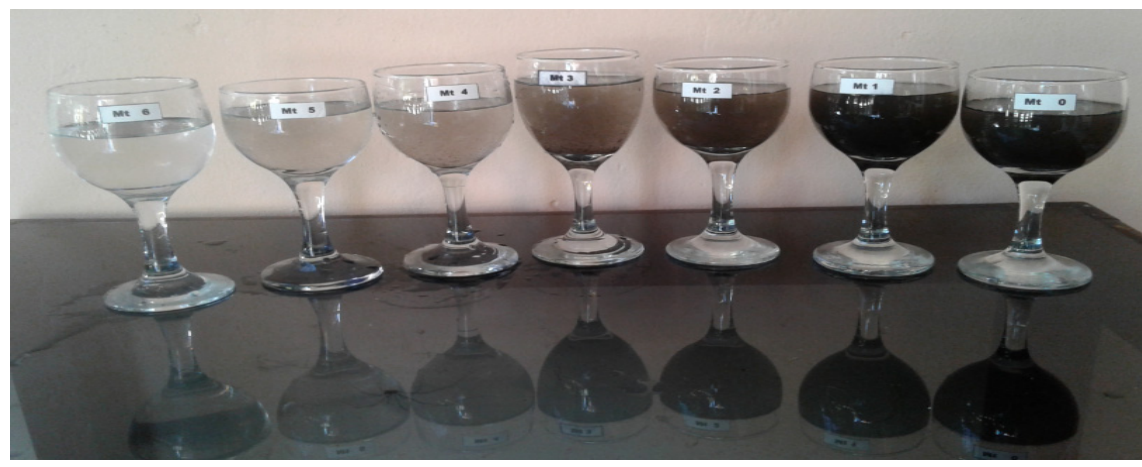

Fig. 6. The level of turbidity of the washing out water, based on the length of filter washing time.

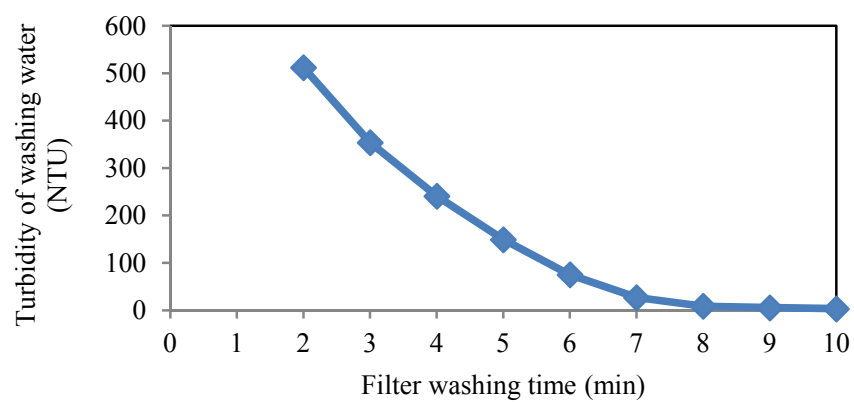

Fig. 7. Graph of turbidity of washing water based on length of filter washing time.

\subsection{Calculation of water pressure}

The water that pushes the existing media layer in the bucket is arranged from the bottom up $15 \mathrm{~cm}$ gravel layer, $5 \mathrm{~cm}$ Ijuk, $10 \mathrm{~cm}$ activated charcoal, $5 \mathrm{~cm}$ Ijuk, and $50-60 \mathrm{~cm}$ sand layer graded $0.15-0.6 \mathrm{~cm}$. The resulting water pressure of the water level of $200 \mathrm{~cm}$ above the datum (the surface of the sand filter) is calculated by the following equation.

$$
\frac{P_{1}}{\gamma}+z_{1}=\frac{P_{2}}{\gamma}+z_{2}+K_{1} \frac{v_{1}^{2}}{2 g}+2 K_{2} \frac{v_{1}^{2}}{2 g}+\frac{f_{1} L_{1} v_{1}^{2}}{2 g D_{1}}+K_{3} \frac{v_{2}^{2}}{2 g}+K_{4} \frac{v_{2}^{2}}{2 g}+h f
$$

where $\frac{p_{1}}{\gamma}=$ water pressure from a reservoir (water level) $=0, \frac{p_{2}}{\gamma}=$ water pressure coming out of the filter, $\mathrm{Z}_{1}=$ water level in the tendon, $\mathrm{Z}_{2}=$ high water in datum, $\mathrm{K}_{1}=$ contraction of water from the tube into the pipe $\varnothing 1^{\prime \prime}=1, \mathrm{~K}_{2}=$ loss of pressure at $\mathrm{L} \varnothing 1^{\prime \prime}=0.2, \mathrm{~K}_{3}=$ loss of pressure at the stop valve $=0.1, \mathrm{~K}_{4}=$ loss of pressure in the filter, $\mathrm{f}_{1}=$ the coefficient of friction in the pipe, $L_{1}=$ long slam $\varnothing 1 "=3 \mathrm{~m}, A_{1}=$ slam sectional area that connects the tank to the outlet sieve, $\mathrm{A}_{2}=$ sectional area of plastic pipe sieve container.

The pressure of water required for cleaning the filter from the calculation, it was found that the height of the cleaning water tanks as high as $200 \mathrm{~cm}$ above the datum capable of pushing dirt out of the sand filter to clean and reusable. Debit, time, speed, and volume of water required for filter washing process as shown in Table 1.

The filter washing experiment by passing water through a graded sand layer that passes at No. 30 sieve and is retained on a No. 100 sieve (sand grading 0.15 to $0.6 \mathrm{~cm}$ ) at a thickness of 50 to $60 \mathrm{~cm}$.

The pressure of washing water as high as $200 \mathrm{~cm}$ above the datum, passing through the filter layer (gravel, ijuk, charcoal, fibers, and sand), at minute 3 , washing water out on the 
pipe of the evaporator dirt with turbidity 512 NTU, turbidity decreases with the duration of washing. At the $10^{\text {th }}$ minute, the turbidity of the water came out to 3.2 NTU Fig. 6 , a graph of the relationship between the turbidity of the washed water with the duration of the washing of the Fig. 7.

Table 1. Debit, time, velocity, and volume of water necessary in washing the filter according to the diameter plastic pipe used

\begin{tabular}{|c|c|c|c|c|}
\hline Pipe Ø (") & Debit/Q (l/s) & Time/T(s) & Speed/V(m/s) & Volume (l) \\
\hline 3" & $0.072-0.082$ & 600 & $0.016-0.017$ & $43.2-49.2$ \\
\hline $4^{\prime \prime}$ & $0.133-0.143$ & 600 & $0.016-0.017$ & $79.8-85.8$ \\
\hline $6 "$ & $0.305-0.315$ & 600 & $0.016-0.017$ & $183.1-189.2$ \\
\hline $8^{\prime \prime}$ & $0.546-0.556$ & 600 & $0.016-0.017$ & $327.6-333.6$ \\
\hline
\end{tabular}

The water discharge that presses the filter layer has to be regulated, the excessive velocity can accumulate the filter sand layer with the dirt, while at a lesser rate it can not push the dirt out leaving the filter, even the dirt can enter in the sand layer, so the filter is difficult to clean.

\section{Conclusions}

Water filtration uses a sand filter from a J-shaped plastic container, the resulting discharge decreases according to the length of use of the filter, after being used for 50 hours, is no longer effective in producing clean water, to optimize the water filtration process is washed after being used for 50 hours. Cleaning the water filter, filled graded sand $0.15 \mathrm{~mm}$ to 0.6 $\mathrm{mm}$ thick $50 \mathrm{~cm}$ to $60 \mathrm{~cm}$ from a J-shaped plastic pipe container, water pressure is needed to push the dirt out of the filter container at speeds of $1.6 \mathrm{~mm}$ to $1.7 \mathrm{~mm} / \mathrm{s}$.

\section{References}

1. Pusat Data dan Informasi. Statistik Kementerian Lingkungan Hidup dan Kehutanan 2014 (Kementerian Lingkungan Hidup dan Kehutanan, Jakarta, 2014)

2. D. Susanto, T.U. Kalsum, Y. Suzantri. Jurnal Media Infotama 10, 2 (2014)

3. B. Shaffin, H. Kishori, B. Apeksha, R. Akshay, Int. J. of Eng. Sci. \& Man. 6, 1 (2016)

4. Saparuddin, M.P. Eisenring, Int. J. of Earth Sci. and Eng. 10, 5 (2017)

5. A.S. Kanagalakshmi, R. Jayanthi, V.T. Anubharathi, SSRG-IJCE 3, 3 (2016)

6. N. Litidamu, T. Young, I. Valemei. Assessment of health impacts from environmental hazards in Fiji, (WHO, Fiji, 2003)

7. V. Nand, M. Maata, K. Koshy, S. Sotheeswaran, Int. J. of Appl. Sci. and Tech. 2, 5 (2012)

8. B. Ruktantichoke, ISB J. of Physics 5, 2 (2011)

9. N. I. Said, A. Herlambang, Pengolahan air bersih dengan proses saringan pasir lambat up flow (BPPT, Jakarta, 1999)

10. L. Huisman, Slow sand filtration (WHO, Geneva, 1974) 